\title{
PENGEMBANGAN GAME EDUKASI SEBAGAI MEDIA PEMBELAJARAN BAGI ANAK BERKEBUTUHAN KHUSUS TUNA RUNGU
}

\author{
Ahmad Zuhdi Alwan ${ }^{1}$, Djuniadi ${ }^{2}$, Manikowati ${ }^{3}$ \\ Universitas Negeri Semarang ${ }^{1,2}$, Balai Pengembangan Multimedia Pendidikan dan Kebudayaan ${ }^{3}$ \\ Email : zuhdialwan22@gmail.com
}

\begin{abstract}
ABSTRAK
Game edukasi merupakan media pembelajaran yang bersifat mendidik agar pengguna mendapatkan pengetahuan dengan cara bermain sambil belajar. Semakin berkembangnya teknologi membuat segala bidang kehidupan untuk saling meningkatkan mutu dan kualitas sistem informasinya guna mengikuti perkembangan di era globalisasi ini. Penelitian ini mempunyai tujuan mengembangkan game edukasi bagi anak berkebutuhan khusus tuna rungu sebagai media pembelajaran yang interaktif dan efektif. Metode penelitian yang digunakan untuk pengembangan game ini adalah scrum, yang memiliki 3 pola proses, yaitu pregame, game, dan postgame. Hasil dari penerapan metodologi scrum pada pengembangan aplikasi game edukasi ini yaitu fitur motif batik tradisional, ornament utama, ornament isian, ornament pelengkap, alat dan bahan, mendesain motif, dan bahasa isyarat pada menu materi dan permainan tebak alat dan bahan, tebak ornament utama, pasang motif batik, dan tebak ornament pelengkap pada menu gim.
\end{abstract}

Kata kunci: game edukasi, tuna rungu, scrum.

\begin{abstract}
Educational games are educational media that are educational so that users get knowledge by playing while learning. The development of technology makes all fields of life improve each other and the quality of the information system in order to keep abreast of developments in this globalization era. This research aims to develop an educational game for children with special needs who are deaf as an interactive and effective learning media. The research method used for the development of this game is Scrum, which has 3 process patterns, namely pregame, game, and postgame. The results of the application of the Scrum methodology in the development of this educational game application are features of traditional batik motifs, main ornament, ornamental stuffing, complementary ornament, tools and materials, designing motifs, and sign language in the material menu and guessing tools and materials, guess the main ornament, attach batik motifs, and guess the complementary ornament on the game menu.
\end{abstract}

Kata kunci: educational game, deaf, scrum.

\section{PENDAHULUAN}

ABK atau anak berkebutuhan khusus seperti tuna rungu tuna netra, dll, memerlukan perhatian khusus dalam proses pembelajaran di sekolah. Khususnya bagi anak tuna rungu, Nirmaladevi \& Raja (2018) mengatakan bahwa kehilangan pendengaran, ketulian, susah mendengar dan gangguan pendengaran adalah berbagai istilah yang digunakan dalam komunitas tuna rungu sebagai kondisi ketidakmampuan untuk mendengar salah satu gangguan parsial atau total. Gangguan pendengaran pada anak tuna rungu mengakibatkan terhambatnya perkembangan bahasa anak, sehingga anak akan kesulitan berkomunikasi dalam proses pembelajaran di kelas dan juga pada saat berkomunikasi dengan orang lain dalam kesehariannya. 
Game edukasi yaitu media pembelajaran berupa permainan yang dapat merangsang daya pikir manusia termasuk meningkatkan konsentrasi dan memecahkan sebuah masalah. Game edukasi telah memainkan peran penting dalam metodologi pendidikan modern (Patton, 2014). Game edukasi dapat mengajarkan anak-anak sejumlah ketrampilan, tetapi untuk menumbuhkan keterlibatan yang cukup sehingga anak ingin belajar, permainan harus cukup menghibur (Johansen, Årsand, \& Hartvigsen, 2018). Jadi dengan belajar sambil bermain dapat menstimulus anak untuk senang belajar. (Puspitasari \& Al Irsyadi, 2018) mengatakan metode pendukung yang biasa digunakan oleh guru ketika menyampaikan materi adalah bahasa isyarat dengan menggunakan gerakan bibir dengan jelas sehingga materi tersampaikan dengan baik kepada siswa.

Game bergenre edukasi dan casual ini dapat melatih kreativitas anak dengan menggunakan tema batik-batik dari berbagai daerah Indonesia pada smartphone berbasis Android. Berdasarkan jurnal penelitian yang dilakukan oleh Osman et al., game mobile memiliki peluang pasar yang besar, terutama pada mobile games. Sekitar $84 \%$ responden menjawab bahwa mereka bermain game menggunakan smartphone. Selain itu, dalam pengembangan Game edukasi harus mengutamakan user interface yang baik (Pratama, 2018) terutama pada pengembangan permainannya yang interaktif karena permainan interaktif ini akan menjadi acuan dalam penyampaian pembelajaran bagi ABK tuna rungu.

Tujuan dengan adanya penelitian ini yaitu untuk mengembangkan game edukasi bagi anak berkebutuhan khusus tuna rungu sebagai media pembelajaran yang interaktif dan efektif. Oleh karena itu, kami merancang aplikasi berbasis android dan PC yaitu berupa game edukasi untuk anak tuna rungu. Aplikasi yang dirancang ini berisi pembelajaran batik disertai dengan bahasa isyarat, permainan dan materi yang berkaitan dengan batik.

\section{METODE PENELITIAN}

Dalam pengembangan game edukasi dilakukan 3 fase yaitu fase pregame, fase game dan diakhiri dengan fase postgame seperti yang ditunjukan pada gambar 1 .

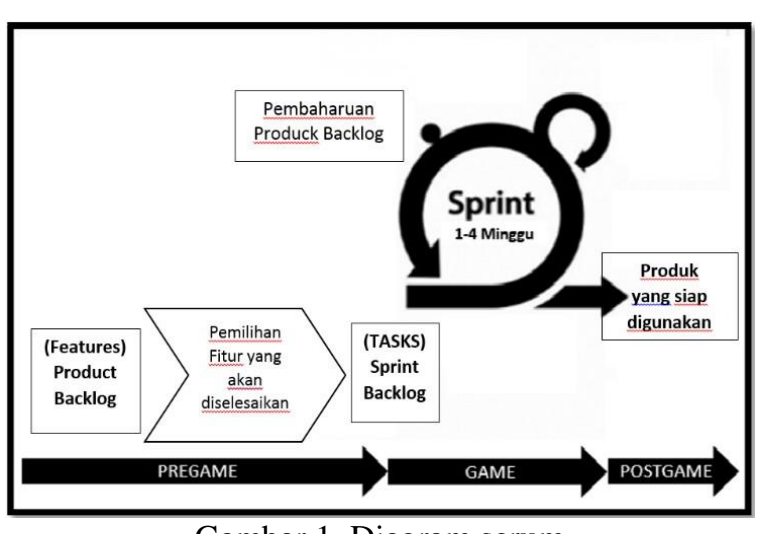

Gambar 1. Diagram scrum

Fase Pregame adalah fase perencanaan yaitu dengan menentukan backlog yang ada meliputi jadwal dan biaya. Pada pengembangan game edukasi ini yaitu dari pengembangan sistem yang lama sehingga dalam fase ini akan terdiri dari analisa terbatas. Setelah perencanaan, kemudian membuat sebuah desain yang berisi implementasi dari daftar backlog. Tahapan ini menyangkut modifikasi desain sistem dan desain di tingkat penggunaannya.

Hasil fase pregame yaitu product backlog. Product backlog merupakan daftar utama semua fungsi yang akan dikembangkan dalam sebuah produk. Pada metodologi scrum tidak diharuskan adanya dokumentasi semua persyaratan diawal pekerjaan. Seringkali sebuah tim scrum dan product owner dimulai dengan menuliskan segala sesuatu yang mudah terlebih dahulu. Product backlog kemudian dikembangkan sesuai kebutuhan dan keinginan pengguna yang akan dilanjutkan pada fase game yaitu dalam bagian sprint. 
Fase game merupakan proses pengembangan pada system aplikasi atau yang sering dikenal dengan istilah sprint. Sprint yaitu sebuah pekerjaan pembuatan aplikasi yang memiliki batasan waktu kurang dari satu bulan. Tahapan sprint digunakan untuk menyelesaikan sebuah fitur dalam pengembangan aplikasi. Setiap tahapan sprint memiliki definisi tentang apa yang dikembangkan, perencanaan yang fleksibel, pelaksanaan pekerjaan dan hasil aplikasi.

Fase akhir dari pengembangan game ini yaitu fase postgame yang merupakan fase penutup berupa testing sebagai proses validasi dan verifikasi pada sistem yang akan diluncurkan. Setelah itu dilakukan langkah dokumentasi dari produk aplikasi yang siap diluncurkan.

\section{HASIL DAN PEMBAHASAN}

Hasil pengembangan aplikasi yang telah dilakukan oleh peneliti menghasilkan sebuah game edukasi dengan menggunakan aplikasi Smart Apps Creator. Pengembangan aplikasi ini dilakukan dengan prosedur penerapan dari metode scrum yang memiliki 3 fase utama yaitu fase pregame, game, dan postgame.

Sesuai dengan metode scrum, langkah langkah pembuatan Game Edukasi ini yaitu sebagai berikut:

\section{Pregame}

Langkah pertama adalah langkah pregame yaitu dengan menentukan sebuah fitur apa saja yang akan dikembangkan sebagai prioritas utamanya. Fitur yang akan dikembangkan ditunjukan pada tabel 1 . Dengan hasil 2 fitur pengembangan pada Game Edukasi ini. Kedua fitur ini yang dinamakan Product Backlog.

Setelah Product Backlog telah ditemukan, langkah selanjutnya yaitu menentukan waktu pelaksanaan pekerjaan aplikasi terhadap setiap fitur yang ditunjukan pada sprint backlog. Berikut tampilan Sprint Backlog yang ditunjukan pada tabel 1 .

Tabel 1. Daftar fitur yang akan dikembangkan

\begin{tabular}{|c|c|c|}
\hline No. & Fitur & Deskripsi fitur \\
\hline 1. & Materi & $\begin{array}{l}\text { Motif batik tradisional, } \\
\text { ornament utama, ornament } \\
\text { isian, ornament pelengkap, } \\
\text { alat dan bahan, mendesain } \\
\text { motif, dan Bahasa isyarat }\end{array}$ \\
\hline 2. & Gim & $\begin{array}{l}\text { Tebak alat dan bahan, tebak } \\
\text { ornament utama, pasang } \\
\text { motif batik, dan tebak } \\
\text { ornament pelengkap. }\end{array}$ \\
\hline
\end{tabular}

Tabel 2. Sprint Backlog

\begin{tabular}{lll}
\hline No. & Fitur & $\begin{array}{l}\text { Perkiraan } \\
\text { waktu }\end{array}$ \\
\hline 1. & Materi & 1 Minggu \\
2. & Gim & 1 Minggu \\
\hline
\end{tabular}

Fase pregame ini adalah tahap analisis perancangan desain awal dari aplikasi yang dibuat, analisis yang pertama yaitu dengan menganalisis desain tampilan aplikasi. Dalam mendesain tampilan aplikasi, penulis menggunakan aplikasi Draw io yang kemudian diterapkan pada aplikasi Corel Draw X7. Berikut adalah desain tampilan awal aplikasi :

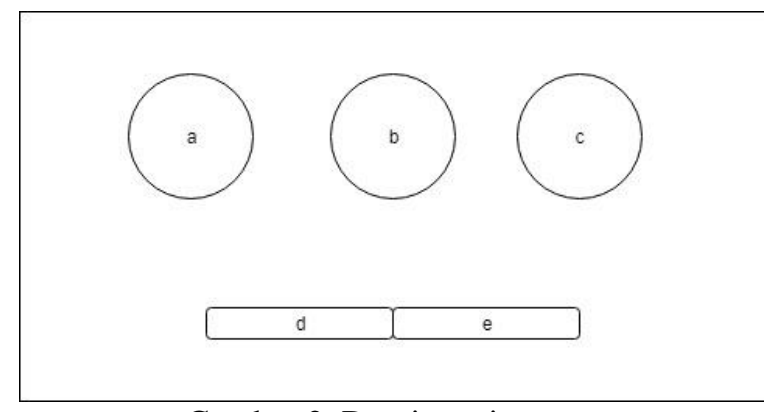

Gambar 2. Desain main menu

Rancangan main menu aplikasi ini terdapat beberapa bagian yaitu: a) Tombol Kompetensi untuk melihat tujuan dari adanya aplikasi ini, b) Tombol Materi untuk melihat materi tentang batik didalam game, c) Tombol Gim untuk memilih dan memulai permainan, d) Tombol Tentang Aplikasi untuk melihat deskripsi aplikasi, e) Tombol 
Kerabat Kerja untuk melihat siapa tim pembuat aplikasi,

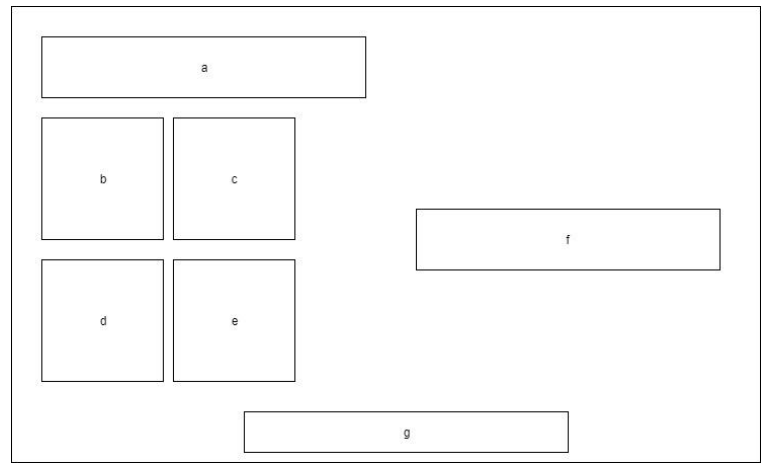

Gambar 3. Desain gim

Rancangan menu pada menu gim memiliki beberapa bagian yaitu: a) Text Pertanyaan, b) Text Jawaban A, c) Text Jawaban B, d) Text Jawaban C, e) Text Jawaban D, f) Tampilan Hasil, g) Tombol kembali ke pemilihan gim.

\section{Game}

Fase game yaitu tahap pengerjaan pengembangan game edukasi. Dalam tahapan ini dilakukan pembuatan sprint backlog pada pengembangkan suatu fitur. Sprint dilakukan dua kali pada fase ini, dimana waktu maksimal pengerjaan sprint yaitu 2 minggu yang menghasilkan waktu pengerjaan dari sprint sampai produk siap release tidak melebihi 1 bulan.

\section{Postgame}

Fase postgame memiliki dua proses yaitu melakukan dokumentasi dan testing. Pada fase ini diawali dengan melakukan dokumentasi berupa pengumpulan Product Backlog dan Sprint Backlog. Dilanjutkan dengan testing sebagai validasi dan verifikasi apakah aplikasi telah sesuai seperti rancangan desain yang sudah dibuat. Berikut tabel hasil testing ditunjukkan pada tabel 2.

Tabel 3. Tabel Pengujian Sistem

\begin{tabular}{llll}
\hline No. & $\begin{array}{l}\text { Fitur yang } \\
\text { diuji }\end{array}$ & $\begin{array}{l}\text { Hasil yang } \\
\text { diharapkan }\end{array}$ & Status \\
\hline 1. & Materi & $\begin{array}{l}\text { Tampilan materi } \\
\text { dan Bahasa }\end{array}$ & Ok \\
\hline
\end{tabular}

\begin{tabular}{ll}
\hline & isyarat berjalan \\
2. Gim $\quad \begin{array}{l}\text { lancer } \\
\text { Dapat bermain } \\
\text { game dengan } \\
\text { sesuai }\end{array}$ \\
\hline
\end{tabular}

Setelah dilakukan dokumentasi dan testing maka produk dapat dinyatakan siap untuk release. Tampilan awal atau halaman awal dari aplikasi seperti yang ditunjukan pada gambar 4, yaitu berupa halaman menu utama.

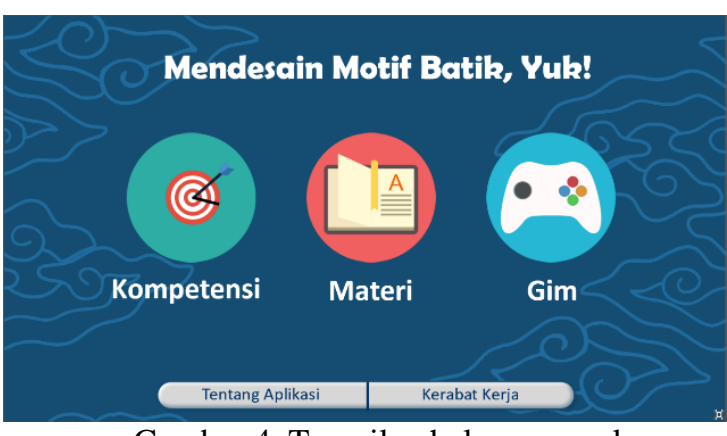

Gambar 4. Tampilan halaman awal

Kemudian pada menu utama terdapat 5 tombol yaitu tombol kompetisi, tombol materi, tombol gim, tombol tentang aplikasi dan tombol kerabat kerja. Berikut adalah tampilan dari setiap tombolnya :

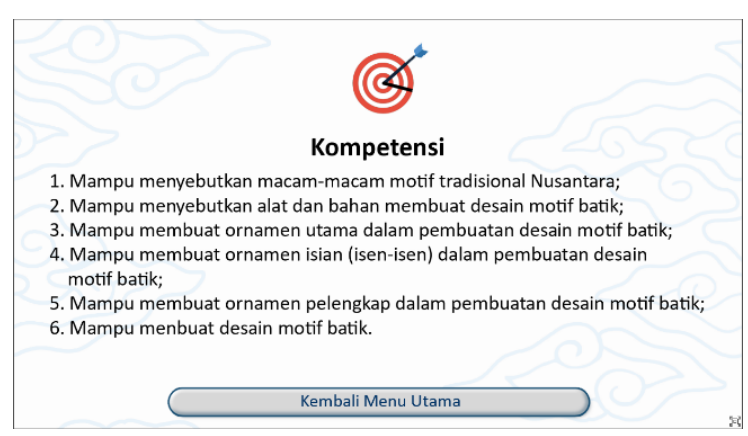

Gambar 5. Menu kompetisi 


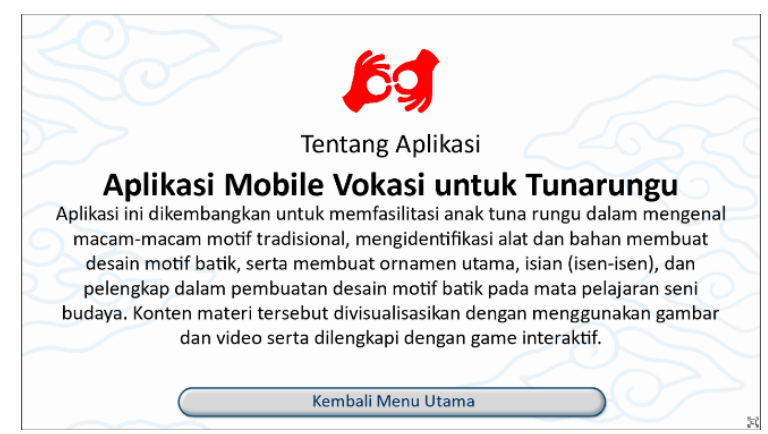

Gambar 6. Menu Tentang Aplikasi

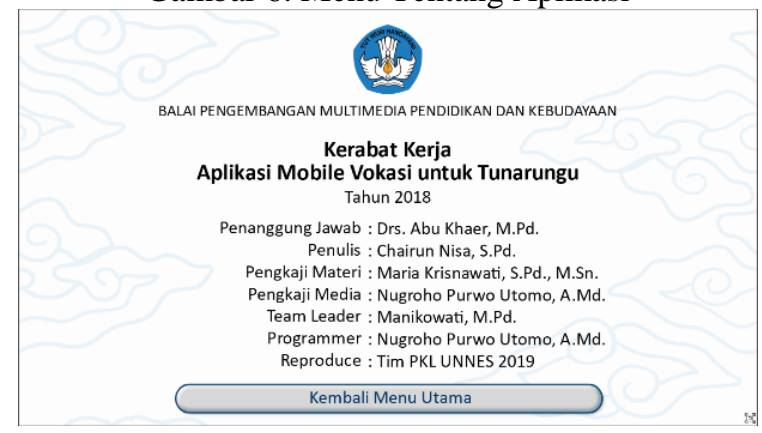

Gambar 7. Menu Kerabat Kerja

\section{Silahkan pilih menu belajar kamu}

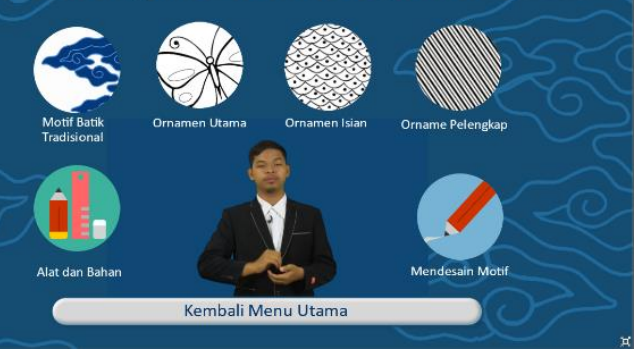

Gambar 8. Menu Materi

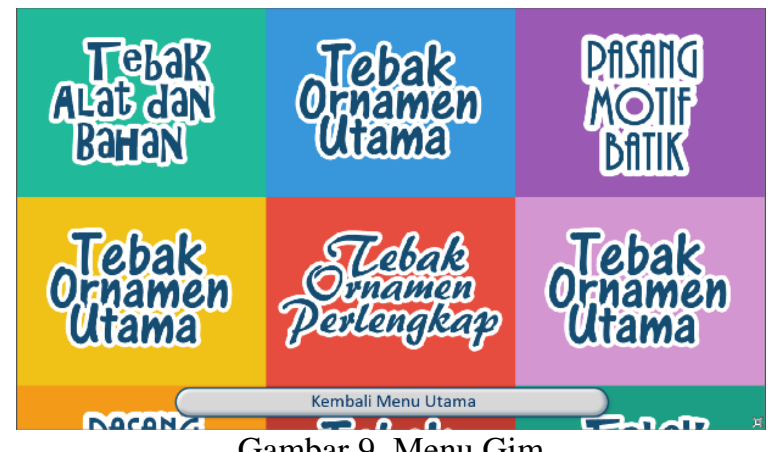

Gambar 9. Menu Gim

Didalam menu materi terdapat 6 sub materi seperti pada gambar 8 meliputi : 1) Motif batik tradisional, 2) Ornamen utama 3) Ornamen Isian, 4) Ornamen pelengkap, 5) Alat dan bahan, 6) Mendesain motif. Kemudian pada menu ini ditambahkan fitur Bahasa isyarat yang berguna agar anak berkebutuhan khusus tuna rungu dapat lebih mudah dalam memahami isi materi tersebut. Gambar 10 adalah contoh isi dalam menu materi.

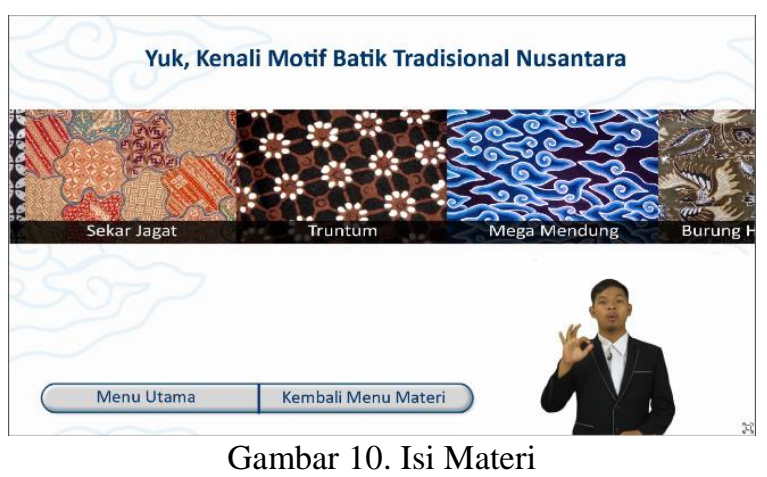

Menu gim memiliki 4 jenis permainan yaitu tebak alat dan bahan, tebak ornamen utama, pasang motif batik dan tebak ornamen pelengkap yang diacak secara random seperti pada gambar 9. Dalam menu gim memiliki tampilan scroll up yang berfungsi untuk menampilkan jenis permainan lainnya dari tampilan layar yang telah diacak dari 4 jenis permainan tersebut. Satu tampilan layer menu gim memiliki 6 pilihan gim yaitu 3 tebak ornament utama, 1 tebak alat dan bahan, 1 pasang motif batik dan 1 tebak ornament pelengkap. Gambar 11 adalah contoh gim tebak alat :

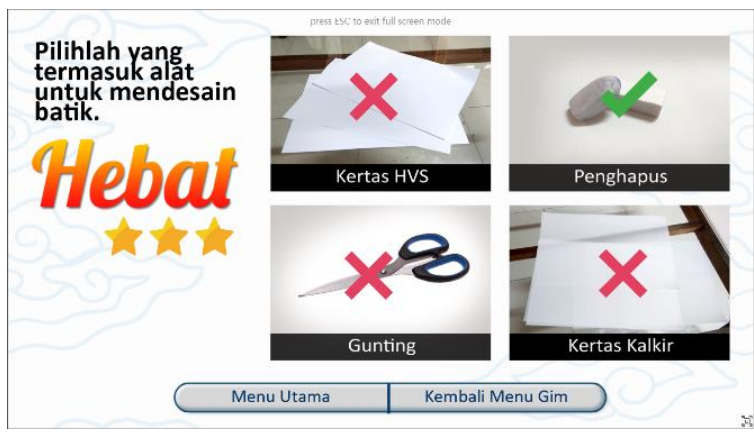

Gambar 11. Isi gim tebak alat

\section{PENUTUP}

\section{Kesimpulan}

a. Pada pengembangan aplikasi game edukasi ini dikembangkan fitur materi dan gim yang menghasilkan 
fitur motif batik tradisional, ornament utama, ornament isian, ornament pelengkap, alat dan bahan, mendesain motif, dan bahasa isyarat pada menu materi dan permainan tebak alat dan bahan, tebak ornament utama, pasang motif batik, dan tebak ornament pelengkap pada menu gim.

b. Pada pengembangan aplikasi game edukasi ini menggunakan metode scrum menghasilkan fitur yang berjalan lancar sehingga metode scrum ini sangat sesuai diterapkan dalam pengembangan game edukasi.

\section{Saran}

a. Game yang dikembangkan belum ada bahasa isyaratnya sehingga diperlukan adanya pengembangan lanjutan mengenai game edukasi ini. 


\section{DAFTAR PUSTAKA}

A. Kusrianto, Batik Filosofi, Motif dan Kegunaan. Yogyakarta, 2014.

Drs. Hamzuri. 1989. Batik Klasik. Jakarta: Djambatan.

E. Adams, Fundamentals of Game Design, 3rd ed. 2014.

Haryono, Bejo. 2004. Makna Batik dalam Kosmologi Orang Jawa. Yogyakarta: Direktorat Permuseuman

J. Whitten and L. Bentley, Systems Analysis and Design Methods 7th Edition, 7th Editio. McGraw-Hill/Irwin; 7th edition (November 22, 2005), 2007.

Johansen, S.-G., Årsand, E., \& Hartvigsen, G. (2018). Making Computer Games that Can Teach Children with Type 1 Diabetes in Rural Areas How to Manage Their Condition. Proceedings from The 16th Scandinavian Conference on Health Informatics 2018, Aalborg, Denmark August 28-29, 2018, (151),7-10.

Ken Schwaber. Agile Project Management with Scrum, Microsoft Press. 2004.

M. A. Osman, A. Z. Talib, Z. A. Sanusi, T. Shiang-Yen, \& A. S. Alwi, "A Study of the Trend of Smartphone and its Usage Behavior in Malaysia," vol. 2, no. 1, pp. 275-286, 2012.
Nirmaladevi, J., \& Raja, K. B. (2018). Quantifying speech signal of deaf speakers with territory specific utterances to understand the acoustic characteristics. International Journal of Biomedical Engineering and Technology, 26(3-4), 365-375.

Pratama, A. (2018). Pengaruh Pengajaran Pemrogaman Animasi melalui Aplikasi Scratch pada Kemampuan Pemecahan Masalah. Joined Journal (Journal of Informatics Education), 1(1), 24. https://doi.org/10.31331/joined.v1i1.61 3

Patton, R. M. (2014). Games That Art Educators Play: Games in the Historical and Cultural Context of Art Education. Studies in Art Education, 55(3), 241-252.

Puspitasari, D., \& Al Irsyadi, F. Y. (2018). Education Game Applicatin ABAS : Ayo Belajar Sholat For Deaf Children ( Case Study: SD-LB Yayasan Rehabilitasi Tuna Rungu Wicara Surakarta ). Skripsi Thesis Universitas Muhammadiyah Surakarta, 1-13.

R. Pressman and B. Maxim, Software Engineering: A Practitioner's Approach 8th Edition. McGraw Hill Education; edisi 8, 2014.

T. Vaughan, Multimedia: Making It Work, Eighth Edition, Eighth Edi. McGraw Hill Professional, 2010. 